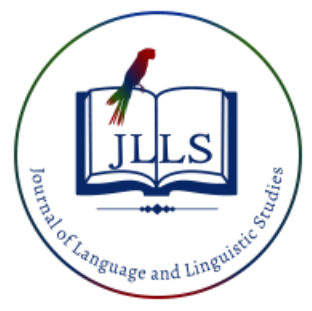

Available online at www.jlls.org

JOURNAL OF LANGUAGE

AND LINGUISTIC STUDIES

ISSN: $1305-578 \mathrm{X}$

Journal of Language and Linguistic Studies, 17(3), 1628-1638; 2021

\title{
Category shifts in simultaneous interpreting in one of Trudeau's speeches
}

\author{
Fida Muhsin Al-Mawla a 1 iD \\ APA Citation: \\ ${ }^{a}$ College of Arts, Wasit University, Iraq \\ Mawla, F.M.A. (2021). Category shifts in simultaneous interpreting in one of Trudeau's speeches. Journal of Language and Linguistic Studies, \\ 17(3), 1628-1638. Doi: 10.52462/j1ls.118 \\ Submission Date:27/05/2021 \\ Acceptance Date:15/08/2021
}

\begin{abstract}
The present study tackles category shifts in simultaneous interpreting in one of the Canadian Prime Minster, Justin Trudeau's, speeches. Translation shifts, especially category shifts, are very common in simultaneous interpreting from English into Arabic. The four types of category shifts, i.e., structure shifts, unit shifts, class shifts and intrasystem shifts, are investigated and analyzed in this study. The interpreting is done from English which is Trudeau's native language into Arabic. After analyzing Trudeau's speech both in his native language, English, and the target language, Arabic, the study comes up with some interesting results. For example, structure shift is shown to be the most common and widely used one; whereas intra-system shift is the least common one. However, this does not mean that the latter rarely occurs. All of the four shifts regularly occur in simultaneous interpreting but in different degrees. No one can say that those shifts undermine or belittle the interpreting process. On the contrary, they suggest that the interpreter is well qualified in both languages that he can smoothy shift between structures, units, classes and intra-systems of both source and target languages without affecting the quality of the interpreting.
\end{abstract}

Key words: simultaneous interpreting; category shift; structure shift; unit shift; class shift; intra-system shift

\section{Introduction}

When any researcher tries to write about simultaneous interpreting, he/she might face the difficulty of getting the needed data. Besides, it would take a long time of exerting efforts to follow up with both the SL and the TL. However, this research is an interesting one since it tackles one aspect of translation shift which is category shift. It follows Catford dichotomy of shifts, i.e., "structure shift, unite shift, class shift and intra-system shift". However, some noticeable remarks about simultaneous interpreting should be stated in the following sections.

\section{Literature Review}

Many academics and linguists wrote about simultaneous interpreting and about some linguistic aspects related to it. For instance, Lin (2019) tackles that issue of cohesion in simultaneous interpreting where he focuses on the semantic relation between two or more levels in the interpreted text, such as, the lexical,

${ }^{1}$ Corresponding author

Email id: falmawla@uowasit.edu.iq 
grammatical, and phonological ones. He attempts to apply cohesion theory in simultaneous interpreting by analyzing the features of the interpreted text. Herman, (2014), on the other hand, studies category shifts in the English translation of Harry Potter and the Philosopher's Stone Movie Subtitle into Indonesian. He finds out that all kinds of category shifts occur in the subtitle and that unit shift is the most dominant one.

Setton (1999), in the same vein, publishes his book Simultaneous interpretation: A cognitive pragmatic analysis to deal comprehensively with different aspects of simultaneous interpretation. He handles the cognitive approach, structures and strategies, pragmatics of interpretation, and some other related aspects.

Moreover, Pöchhacker (1995), in his paper "Simultaneous Interpreting: A Functionalist Perspective" discusses a number of methodological and theoretical issues that arise when professional simultaneous conference interpreting is studied according to the functionalist theory of interpreting and translation proposed by Hans J. Vermeer, i.e., skopos theory.

By the same token, Sugianti (2017) published a paper entitled "English noun phrase translation shift in the novel 'The Davinci Code"'. In this study, he analyzes the type of shifts used by the translator of that novel when attempting to render it. The translation has been done from English into Indonesian.

\section{Remarks about Simultaneous Interpreting}

Simultaneous interpreting can be defined as "a mode of interpreting in which the speaker makes a speech and the interpreter reformulates the speech into a language his audience understands at the same time (or simultaneously)". Simultaneous interpreters usually do their job in interpreting booths; although they can also use a portable interpreting equipment; i.e., 'bidule' or 'chuchotage' without whispering or a booth, (An official site of the European Union).

Although simultaneous interpreting is quite difficult and complicated, it is one of the most prevalent forms of interpretation. In simultaneous interpreting, the interpreter has to render all what has been uttered "within the time allowed by the speaker's pace without changing the natural flow of the speech". (Day Translations, 2018)

The Simultaneous interpreter usually, as mentioned by Fantinuoli (2017), experiences different cognitive activities, such as, listening, comprehension, translation, production, and finally monitoring. They all need a precarious balance in order to produce acceptable interpreting. In other word, the three main actions that the simultaneous interpreter should do are:

1) Listening actively (to understand)

2) Analyzing (to structure the message)

3) Reproducing (to communicate)

A skillful simultaneous interpreter should have the ability to guess what the speaker can utter, especially if the speaker's language has a completely different syntactic structure to the other language interpreted into. It is very necessary to the simultaneous interpreter to have the ability to be calm and remain as such under any kind of pressure, and to "be resilient to stress". The interpreter's active language is usually under a kind of pressure as he/she is speaking and in the same moment he/she is listening and analyzing. Consequently, it is very necessary for the interpreter to have "excellent mothertongue or active language skills". 'Interference' is very likely to happen from the passive, i.e., heard 
language or source language to the active i.e., target language or spoken language. This chance is likely to happen in simultaneous interpreting. In this case, more attention has to be given by interpreters in order to improve their output or product. This means avoiding 'false friends', cutting up long sentences into shorter ones as well as getting away from the source language syntax, (An official site of the European Union).

The interpreter should interpret all that is uttered by the speaker at the same moment as he/she is giving his/her speech. There must be no waiting time or a pause between the process of interpreting and that of receiving what is being uttered. The interpreter is allowed to take only a 'short pause' to process what is said by the speaker. Simultaneous interpretation is often used at political conferences, Presidential speeches and at the United Nations, (Day translation, 2018).

Pöchhacker (1995, P.35) states that, the relationship between the interpreter and the client in conference interpreting is "not as straightforward, at least in analytical terms, as in the case of (written) translation". In conferences, the interpreter's client has no desire for the text to be rendered; but wants "a much more complex communicative event".

Simultaneous interpreting involves the oral rendering of the delivered speech. The interpreter reformulates the speech of the source language into the required target language, as it is the case in a written translation. The interpreter's job is to "deliver all the semantic elements", including its tone, in the original speech successfully. Moreover, he/she also needs to convey the core and intent of the original message that the speaker wishes to convey. (Day translation, 2018).

\section{Simultaneous Interpreting: Pros and Cons}

The complexity of simultaneous interpreting is supposed to come from the fact that it needs a variety of cognitive tasks that should be carried out concurrently, (Lambert, 2004). Simultaneous interpreting needs "language comprehension-related tasks, such as word recognition semantic and syntactic decoding", that should be carried out simultaneously as "language production-related tasks, such as lexical selection and semantic and syntactic encoding” (Seeber, 2015, pp. 82,85).

Besides, simultaneous interpreters need to regularly boost their language and interpreting skills. They have to be sure and fully confident of the capacities and skills of their own language. Expertise of simultaneous interpreters is greatly needed since the number of international events in different parts of the globe has increased. Interpreters' skills when used properly is one of the preferable strategies to deliver the intended message to multilingual recipients. Simultaneous interpreting is of great importance to politicians, businesses and individuals for effective communication and to make sure that there are no more language barriers and the message is delivered efficiently in the target languages spoken by other recipients (Day Translation, 2018).

In the same vein, Setton (2005) mentions that interpreters have to be skillful and proficient in both the SL and TL they interpret between. Moreover, they need to have some knowledge and to prepare well for the topics to be delivered. Besides, they need to have possible access to visual information and meetingrelated auditory. They also have to be equipped with efficient technical tools. In case of facing certain features of identified input problems that trigger for simultaneous interpreters, this kind of problems "do not appear to be limited to inhibiting ordinary language comprehension". However, those problems only come to appear if language production and multi-lingual language comprehension overlap. These problems include density and speed of speech, speakers' accents, complex syntactic structures and presence of a number of source speech, (Gile, 1995). 
The interpreter delivers real-time interpreting when doing his job in simultaneous interpreting, and the speaker does not wait for him/her nor pause to render that part of the speech which has been just said. The speaker may continue his speech while the interpreter does his/her work of interpreting into the other language. Furthermore, the interpreter is usually isolated and faraway from the conference participants. Therefore, it is feasible to have this particular delivered speech interpreted in a variety of languages immediately. The recipients can choose the language that they want by choosing one from their own headsets channels, (Day Translation, 2018).

Simultaneous interpreters are usually governed by some code of ethics formulated either by the institutions and agencies themselves or by professional associations, (Venuti, 2004, p.500). Schweda Nicholson (1994, p.84) mentions that interpreters should be "panes of glass" that "allow for the communications of ideas, once again, without modification, adjustment or misrepresentation".

One of the principal advantages of simultaneous interpretation is "maintaining the smooth flow of the presentation". In this type of interpretation, time is precious and there is only a short period of delay before the interpreter delivers the information from the SL into the TL. During most types of conferences, it is common and typical for participants to have a look or read conference handouts and materials, talk among themselves, and look around checking others around. This means that their attention is scattered. Simultaneous interpretation is typical for grand multilingual conferences.

Simultaneous interpretation usually keeps the audience attentive and focused. When we have simultaneous interpreting, full attention has to be given by event participants to what is delivered by the speaker by means of interpreting in order to understand the intended message. They have to listen attentively to the interpreters. (Day Translation, 2018).

Pöchhacker (1995, p.36) mentions five features that are characteristics for conference typology: group cultural homogeneity, structural complexity degree, visual support material, informational intensity, and information flow. These features must be taken into consideration by the interpreter.

Nevertheless, simultaneous interpretation is not directly interactive like other types of interpreting. High concentration is demanded from the interpreter when he/she does simultaneous interpreting. That is why they need some rest every half hour. Typically, it requires two interpreters per target language which makes it more expensive. This particular type of interpreting requires special equipment, such as, conference headsets, soundproof booths, wires from the booths to the microphones and headsets. Cameras and video screens might be needed by the interpreters to see the speakers if the interpreters' booths are located in some different places from the conference, (Day Translation, 2018).

Sometimes simultaneous interpreters need to amend or make some adaptation during their work. The method of adaptation is very common in some situations of simultaneous interpreting. Consider the following examples cited by Vinay and Darbelnet (2004, p.135). They mention that a simultaneous interpreter has adapted the word 'cricket' into 'Tour de France' in a context to refer to one of the most popular sports when interpreting to the French delegate. Then he reversed the adaptation and spoke of cricket when he interpreted for his English client.

There are many difficulties an interpreter may face during his/her simultaneous interpreting process. Fontinuoli (2017) mentions those difficulties as problems facing Automatic Speech Recognition; but they cause problems to human interpreters as well:

1- Using spoken language with a variety of styles can cause a problem where there might be hesitations, mispronunciations, etc. or using careful vs. casual style. 
2- Social or regional dialects can cause problems. Speaker variability should also be taken into consideration, such as the voice and speaker's unique physical features.

3- Another problem is ambiguity which is inherent in all natural languages. For example, homophones, like, "site" vs. "sight" vs. "cite" are big problems. Besides, word boundary ambiguity, as, "night-rate" vs. " nitrate" are hard to decide which one is actually intended.

4- Background noise is another issue where there are some speakers nearby or other noises, such as project humming.

5- Speeches can be uttered at different speed from very slow to very high. The problem appears when speakers speak fast uttering words poorly.

6- Body language or non-verbal signals are usually used along with verbal communication, such as hand gestures, posture, and facial expressions. This is another problem facing an interpreter.

All the above mentioned problems may hinder the interpreting process if not considered by the interpreter.

\section{Importance of Simultaneous Interpretation}

Interpretation is one of language services which is concerned about ensuring effective communication and proper understanding by breaking down language barriers. It is so easy for a participant to follow the speaker's speech almost immediately with the aid of simultaneous interpreting.

Pöchhacker (1995, P.39) An interpretation should sound like an original speech, and that it is at its best when listeners forget that they are listening to an interpreter rather than the original speaker.

There are several reasons that show the importance of simultaneous interpretation, such as:

- Simultaneous interpretation avoids the time-consuming task of rendering the speeches and documents in the languages of all participants. Every attendant becomes aware of everything said or discussed since the interpreting is done immediately and quickly.

- It gives the delegates the opportunity to listen to what is said in their mother tongue. Besides, it provides an efficient communication when allowing delegates to enjoy an equal chance of sharing their ideas and knowledge.

- Messages cannot be lost as the interpreting is always done real-time. The participants are allowed to express their thoughts, views and ideas in their own languages in a proper way.

- In simultaneous interpreting, accuracy is always confirmed as the interpreter immediately renders what is said by the speaker. Multilingual conferences usually gain better results as communication is achieved correctly and properly with the interpreting. All delegates can freely communicate in their own native languages and in the same time, they know that they can fellow other delegates properly. (Day Translation, 2018).

Moreover, the importance of simultaneous interpreting comes also from the domain it works in other than conferences. Community interpreters, for example, perform their work in different medical, legal, as well as educational situations. Not only that, but they work in other situations, such as, requests for asylum, hospital admission, court appearance and application for welfare, (Venuti, 2004, p.500). 


\section{Translation Shift}

When we talk about 'category shifts', we have to mention Catford's name since he is the first translation theorists who introduced it as a term. Catford (1965, p.73) mentions that "by shifts we mean the departures from formal correspondence in the process of going from the SL to the TL". Furthermore, he maintains that this shift is made to bring the suitable natural equivalent of the ST message and apply it to the target text (Catford,1965, p.76). When it is difficult to find formal correspondence to any syntactic item in the TL, translation shift occurs (Machali, 1998, p.3). Bell (1991, p. 33), in the same vein, says "'to shift from one language to another is, by definition, to alter the forms".

Catford (1965, p.73) states that when the translator cannot carry out his job by adhering closely to the linguistic form of the ST, textual equivalence is needed through translation shift. He divides translation shift into two basic types, i.e., level shift and category shift. The former shift refers to an "SL item at one linguistic level has a TL translation equivalent at a different level". This means that shifts are simply "shifts from grammar to lexis and vice-versa". Transposition, i.e., translation shift, according Sugianti (2017, p.11) is the shift of word class as change of grammatical category as a result of two different linguistic systems and cultures and it is unavoidable in translation.

Category shifts, on the other hand, means "the departures from formal correspondence in translation" (Catford, 1965, p.76). Formal correspondence refers to any grammatical category in the TL that may occupy the same position in the TL system as the given SL category in the SL system (Machali, 1998, p.13).

Machali (1998, p. 152), as cited in Sugianti (2017), further suggests the types of translation shifts when she divides those shifts in translation into: optional shifts and obligatory shifts. The former shifts refer to a case of shift that is caused by the translator's discretion. The reason behind calling it 'optional' is that the translator could have chosen the closer equivalent clauses with the readers' orientation in the TL text. However, the other type of shifts is called 'obligatory shifts' which refer to the kinds of shifts that the translator opts for when he/she finds it difficult to find formal correspondence in the TL. Often, grammar dictates the occurrence of that shift.

Moreover, Machali (1998, p.160) highlights that the two main sources of translation shifts are 'SL text-centered shift' and 'TL text-centered shift'. The former shifts are further divided into three types: Firstly, grammatical shift, that mainly includes tenses, particle markedness and foregrounding. Secondly, shifts that are connected to cohesion and ellipsis are the most common ones. Thirdly, textual shifts that basically concern embodiment of interpersonal meaning and genetic ambivalence. The TL text-centered shift causes the main problem to translators when trying to achieve information (referential) explicitness, effectiveness and pragmatic appropriateness which includes culture.

Nida and Taber (1969, p. 171) state that 'Modifications' are the most widely used meaning shifts in the transfer process. Those modifications involve generic and specific meaning. These kinds of shifts can go in either direction from specific to generic or vice versa. Often these shifts lead to inaccurate and incorrect translation. Any difference of the system in both languages may cause a shift. The difference can be in the form of structure or vocabulary. The structure shift usually does not cause any change in the message or the original text meaning. Whereas, the shifts caused by the vocabulary may result in a meaning shift. 


\section{1 Category Shifts}

Catford (1965) highlights that category shift is divided again into structure shifts, class shifts, unit shift, and intra-system shifts.

\subsection{Structure Shift}

Catford (1965) considers structure shifts the most frequent type of shifts that may occur at all ranks. Any world language contains rules of grammar and by applying those rules, we can produce meaningful patterns or stretches. We can apply that abstract category to all units in a language grammar that accounts for the various ways in which one particular unit might be realized by the adjacent one. Yet, sometimes, a unit might be realized by another unit above it. Catford calls this phenomenon 'rank shift'. It can occur at all ranks in grammar. It can also occur at other ranks, like, group rank.

Any language can exhibit a noticeable number of differences in both the type of patterns existing in other languages and in the realization of similar patterns existing in that language. The distinction between surface realizations of linguistic relations and their deep representations designates a noticeable point for structure shift analysis. In other words, structure shift involves a change in the syntactic structure between the ST and TT (Herman, 2014, p.33).

\subsubsection{Unit Shift}

What is meant by 'unit shift' is the changes of rank; i.e., "departures from formal correspondence in which the translation equivalent of a unit at one rank in the SL is a unit at a different rank in the TL" (Catford, 1965, p.79).

It often includes some shifts from a word to a morpheme, a phrase to a word, a sentence to a clause and vice versa.

Unit shifts could be from high level to lower level or from low level to higher level. As Herman (2014, p.34) puts it, this shift is the result of the differences in the component meaning amount in different concepts.

\subsubsection{Class Shift}

Class shift, on the other hand, "occurs when the translation equivalent of an SL item is a member of a different class from the original item" in the TL (Catford, 1965, p.78). Hatim and Munday (2004, p. 1456) further elaborate that it is clear that structure shift usually entails class shift, although this may be demonstrable at a secondary degree of delicacy only. It is a change in word class. This is because of the "logical dependence of class on structure" (Catford, 1965:119).

\subsubsection{Intra-System Shift}

Finally, intra-system shift denotes the shift that "occur internally, within a system; that is, for those cases where SL and TL possess systems which approximately correspond formally as to their constitution, but when translation involves selection of a non-corresponding term in the TL system" (Catford, 1965, p.80). Hatim (2013, p. 19) gives an example of it by mentioning that an SL singular may become a TL plural despite the fact that both languages have an available number system. For example, In Arabic, we say (wezirat almar'a) in the singular form; whereas its translation in English is "Minister of Women or Women Minister" where the plural form is used instead of the singular. Both systems occur in both Arabic and English; yet it is translated in that way. 
In the same vein, Herman (2014, p.34) mentions the same abovementioned idea about the internally occurred changes within a system. He further adds that they are dealt with only on the assumption that formal correspondence between the TL and the SL has to possess approximate systems. In translation, the equivalence occurs at a "non-corresponding term in the TL system". For instance, every world language has its own systems of articles, number, pronouns, deixis, etc. In this case, intra-system shifts occur when an item is plural in the ST and its textual equivalent is singular, or vice versa. This implies a shift in number although both the SL and the TL have the same number system, as in the above Arabic example.

\section{Discussion and Analysis}

The data of the present study are to be tackled by investigating one of Justin Trudeau, the Canadian Prime Minister's, speeches. He delivered that speech during Coronavirus crisis and it is available at: https://www.youtube.com/watch? $\mathrm{v}=$ TcJaxjzNjqo. By listening to both the source language and the target language, the researcher tries to analyze the data according to Catford's dichotomy of category shifts. The four division of category shifts, i.e., structure, unit, class and intra-system are going to be focused on.

The analysis is not to assess the quality of interpreting nor to decide whether it was adequate or not. However, the main focus is to be on the rendering the four subdivision of category shift. The following items from that speech are to be analyzed:

1. "...who don't have access to sick leave". This extract has been rendered as: (laysa ladaihum ijaza maradhiya).

There is a structure shift and class shift since 'sick leave', i.e., Adj+N, is rendered by $\mathrm{N}+\mathrm{Adj}$. which is the norm in Arabic.

2- "...every two weeks", " ...fourteen weeks", etc. are translated as (kul isbua'ain) and (arba'ata asher usbu'an) respectively. The former is a low level unit shift where two words are rendered as one word; whereas the latter is high level unit shift where one word is rendered as two words.

3- "workers who have to stay home" is interpreted as

(alayhum an yabqau fi buyutihim). We notice the insertion of the Arabic preposition which is a class shift and at the same time structure shift.

4- "People who fall ill or have been placed in quarantine or have to self-isolate" is rendered into:

(men yatamaradh aw wadha'a nafsahu fil hajr alsihi)

"Fall ill" which is V+ Adj has become a single word verb. This is, of course, a class shift and structure shift, as well. As for the translation of both "quarantine and have to self-isolate", the interpreter tries to mix them in one concept: (wadha'a)...where we have a verb plus reflexive pronoun as an object and a prepositional phrase. This is a unite shift, a class shift and a structure shift, as well. Besides, there is an intra-system shift in using the Arabic definite article twice where the ST equivalent does not have it here.

5- "Many people are wondering ..." is interpreted as:

(yatasa'el aladeed minal ashkhas)

The structure shift is very clear in the $\mathrm{SL}$ as $\mathrm{S}+\mathrm{V}$; whereas, the TL is V+S.

6- " " who are in vulnerable situation" is rendered into:

(ya'ishun wadhiyat hashasha sihiya). 
There is a unit shift here and at the same time a structure shift where the linking verb "be" is followed by a prepositional phrase. The TT has become a sentence with a plural present verb followed by adverbial phrase.

7- "during these uncertain times" is interpreted as:

(fi hathihi alawqat alaseeba)

There is an intra-system shift where the plural demonstrative adjective in the ST is rendered into singular demonstrative one due to the Arabic grammar system.

8- " young kids will find the coming months especially difficult with school closures" is rendered into:

(sayajud alatfal fil ash'hur alqadima su'ubat ma'a ighlaq almadaris)

There is a unit shift in rendering "young kids" into (alatfal)

The same item can be said to undergo intra- system shift due to the existence of the Arabic definite article. Moreover, there is a class shift which also entails a structure shift in the rendition of the adjective "difficult" into a noun in the TL. There is, again, a structure shift and class shift in the phrase "school closures" which is interpreted as (ighlaq almadaris), where the singular noun becomes plural and viceversa.

9- "parents" is rendered into: (alabaa wal umahat)

Here, the single word "parents" in the SL is rendered into two words in the Arabic interpretation. This is a unit shift.

10- "Canada Student loans" is rendered into:

(altalaba alatheen ladaihum qurudh)

There is a unit shift here.

11- "These are some of the things" is interpreted into:

(hathihi ba'adh alijra'at)

Here is again an intra-system shift, especially in the use of the demonstrative adjective in both texts.

12- "no matter where you live, what you do or who are you" is rendered into:

(mahma yakun makan wujudek wa ka'inan man takun)

Regardless of the missing items, here we have "structure shift, class shift and intra-system shift" concerning the pronoun "you" which has many realizations in Arabic, but only one in English.

13- "Our work is to support you. Our job is to give you a helping hand" has been translated as:

(nahnu naltazem ma'akum bianana sanurafiqekum belda'am wal awn)

Here again, we have a combination of shifts, i.e., "structure shift, class shift and unit shift".

14- "For farmers and primary food producers, we will boost farm Credit Canada" is rendered into:

(bilnisba lilmuzari'in wa muntiji almawad alghitha'iya sanad'amuhum)

We have a structure shift and class shift. Moreover, there is an "intra-system shift" in the use of the definite article in the Arabic text. 


\section{Results and Conclusions}

\subsection{Results}

The analysis results show that out of the four category shifts, the structure shift is the most common and widely used shift in simultaneous interpreting from English into Arabic according to the fourteen chosen sentences. It gains $92.8 \%$. Class shift which usually entails structure shift comes in the second place with $71.4 \%$. Unit shift comes in the third place with $57.1 \%$. The last one is the intra-system shifts with $42.8 \%$.

Table 1. Result

\begin{tabular}{|l|l|l|l|}
\hline No. & Type of Shift & Recurrence & Percentage \\
\hline 1 & Structure shift & 13 & $92.8 \%$ \\
\hline 2 & Unit shift & 8 & $57.1 \%$ \\
\hline 3 & Class shift & 10 & $71.4 \%$ \\
\hline 4 & Intra-system shift & 6 & $42.8 \%$ \\
\hline
\end{tabular}

\subsection{Conclusions}

As it is well known, Simultaneous interpreting is not an easy task to be done and it is very complex activity that involves the human mind and requires great skills. The following are the most prominent conclusions of this study:

1- Category shifts with all its four types happen all the time in simultaneous interpreting from English into Arabic.

2- Structure shift is the most common among the other shifts.

3- Class shifts also happen all the time and they entail structure shifts.

4- Unit shifts, in the same vein, regularly occur in simultaneous interpreting.

5- Intra-system shifts are the less common among the other shifts; but this does not mean that they rarely happen.

6- All those category shifts occur in simultaneous interpreting due to the completely different structural systems of both Arabic and English.

\section{References}

Catford, J. C. (1965). A Linguistic Theory of Translation. Oxford: Oxford University Press.

Day Translation. (2018). at: https://www.daytranslations.com/blog/simultaneous- interpreting/

Fantinuoli, Claudio. (2017). "Speech Recognition in the Interpreter Workstation" in Translating and the

Computer 39 proceedings. Geneva: As Ling, https://www.tradulex. com and www.asling.org

Hatim, B. (2013). Teaching and Researching Translation. 2nd ed. London: Pearson. 
Hatim, B. \& Munday, J. (2004). Translation: An Advanced Resource Book. London: Routledge.

Herman, M. Pd. (2014). "Category Shifts in the English Translation of Harry Potter and the Philosopher's Stone Movie Subtitle into Indonesia (An Applied Linguistics Study)" in IOSR Journal of Humanities and Social Science, Volume 19, (Dec. 2014), PP 31-38. www.iosrjournals.org

Lin, Yangqiong. (2019). "A Study of Cohesion in Simultaneous Interpreting" in Advances in Social Science, Education and Humanities Research, volume 332, International Conference on Contemporary Education and Society Development (ICCESD 2019)

Machali, R. (1998). Pedoman Bagi Penerjemah. Jakarta: Grasindo.

Nida, E. and Taber, C. R. (1969). The Theory and Practice of Translation. Boston: Brill. Official site of the European Union at: https://ec.europa.eu/education/knowledge-centre-interpretation/conferenceinterpreting/simultaneous-interpreting_en

Pöchhacker, Franz. (1995). Simultaneous Interpreting: A Functionalist Perspective. Hermes, Journal of Linguistics, 14.

Schweda Nicholson, N. (1994). "Professional Ethics for Court and Community Interpreters" in D. H. Hammond (ed.) Professional Issues for Translators and Interpreters, Amsterdam: Benjamins.

Seeber, Kilian. (2015). Routledge handbook of interpreting, 1st Edition. Chapter: 5, Publisher: Taylor and Francis, Eds. Holly Mikkelson, Renée Jourdenais, 79-95.

Setton, R. (1999). Simultaneous interpretation: A cognitive pragmatic analysis. Amsterdam/Philadelphia: John Benjamin.

Setton, R. (2005). "So What is so Interesting about Simultaneous Interpreting?" SKASE Journal of Translation and Interpretation I, 70-84.

Sugianti, D.N.S. (2017). English noun phrase translation shift in the novel "The Davinci Code" in Journal of Language and Translation Studies. Available at: <https://ojs.unud.ac.id/index.php/ej1/article/view/28604>.

Venuti, Lawrence. (2004). "Translation, Community, Utopia" in The Translation Studies Reader Ed. By Venuti. London: Routledge.

Vinay, Jean-Paul and Darbelnet, Jean. (2004). "A Methodology for Translation" in The Translation Studies Reader Ed. By Venuti. London: Routledge.

\section{AUTHOR BIODATA}

Dr. Fida Muhsin Matter Al-Mawla, PhD in Linguistics and Translation from Mustansiriyah University, Iraq, He is currently the Dean of the College of Arts, Wasit University, as per the nomination of the Iraqi Ministry of Higher Education and Scientific Affairs. She has been teaching English and Arabic Translation for 20 years. She founded the Department of Translation at the College of Arts, Wasit University in 2012 and headed the Department for six years. She has published many research papers apart from two books. Moreover, she has supervised many theses for Master students and has been a member of examining committees for PhD and MA students in different Iraqi Universities. 